\title{
The effect of directional wind components on survival of Little Penguins Eudyptula minor
}

\section{B. Ganendran ${ }^{1} \quad$ L. A. Sidhu ${ }^{2} \quad$ E. A. Catchpole ${ }^{3}$ P. Dann ${ }^{4}$ L. E. Chambers ${ }^{5}$}

(Received 31 January 2011; revised 15 November 2011)

\begin{abstract}
We live in an age of increased awareness of climate change and its potential effects on our ecosystems. Here we look at the effect of one aspect of climate, directional wind components, on the survival of Little Penguins Eudyptula minor on Phillip Island in southeastern Australia, using mark-recapture data gathered over a 42 year period since 1968 . We apply biologically realistic age structures for the survival and recapture probabilities, and use mean seasonal wind magnitudes from the four cardinal compass directions as covariates in our modelling of the survival probability. Results indicate that first year survival is most affected by southerly winds in the winter prior to the chick's birth, which increase survival, and by easterly winds in the summer of hatching/fledging, which decrease survival. Adult survival is most affected by increasing northerly winds in the autumn following moult
\end{abstract}

http://journal austms.org.au/ojs/index.php/ANZIAMJ/article/view/3956 gives this article, (c) Austral. Mathematical Soc. 2011. Published December 6, 2011. ISSN 1446-8735. (Print two pages per sheet of paper.) Copies of this article must not be made otherwise available on the internet; instead link directly to this URL for this article. 
(positively) and by easterly winds in the preceding summer (negatively). For both first-year and adult birds, increasing easterly summer wind is associated with decreased survival, possibly due to reduced flows of nutrient rich waters from western Bass Strait.

\section{Contents}

1 Introduction

C1013

2 Data and methods

C1016

3 Results and discussion

C1019

3.1 First year survival . . . . . . . . . . . . . . . . . . . . C1019

3.2 Adult survival . . . . . . . . . . . . . . . . . . C1022

4 Conclusion

C1025

References

C1026

\section{Introduction}

Climate affects seabirds throughout the world both physiologically and behaviourally, and indirectly through their food chains and competitors $[1,2,5]$. Within the Australian region, responses by seabirds to observed climatic changes vary by location and species [5]. Wind can influence the lives of seabirds in many ways. Strong winds and severe storms are known to affect seabird breeding participation, timing and success of breeding and mortality $[17,13]$. Wind related mixing of the water column is associated with foraging efficiency [23] and wind driven water movement is linked to marine productivity in Bass Strait [20]. Mickelson et al. [20] discussed the effect of sea temperature and wind in Bass Strait on the breeding success of Little 
Penguins Eudyptula minor on Phillip Island. They used as covariates sea temperatures at two locations - one near the penguin colony, and a second at the eastern end of Bass Strait where the East Australian Current intrudes into Bass Strait - as well as the sea temperature gradient between the two sites. They found that the arrival of cooler waters brought in by west winds decreased the sea temperature gradient, and that this was associated with increased weights of adult penguins four months later. They hypothesised that the cooler waters were associated with higher marine productivity, and hence an increased supply of the fish on which the penguins feed. Ropert-Coudert et al. [23], in a study of 20 Little Penguins over two years, found that foraging efficiency was higher in the year when waters were thermally well stratified and lower when waters were more mixed (due to a series of storms, with four days of winds greater than $50 \mathrm{~km} \mathrm{~h}^{-1}$ ). This led them to suggest that an increased degree of vertical mixing may lead to a lesser concentration of fish, resulting in lower foraging success.

Every evening at dusk, up to 1500 Little Penguins come ashore on Summerland Beach on Phillip Island, Victoria, in southeastern Australia $\left(38^{\circ} 30^{\prime} \mathrm{S}\right.$, $145^{\circ} 10^{\prime} \mathrm{E}$, see Figure 1), in front of up to three and a half thousand people. This iconic 'Penguin Parade' generates tens of millions of dollars annually in tourism revenue for the region. The breeding season of the Little Penguin lasts from July to March, with egg laying generally taking place from August to December. During incubation, which lasts around 35 days, and for the first two weeks of a chick's life, parents take turns on guard duty [22]. After fledging at around eight to ten weeks of age, chicks go to sea, returning to breed at two or three years of age. From then on, most breed every year [11]. Fledging is a hazardous event in the life of a penguin chick, and most do not survive their first year of life [27]. For an adult, the two major events each year are its breeding activities and its moult. The moult takes place over two to three weeks between February and April and the penguin must stay on land and fast while waiting for new feathers to grow. The periods after moult and in late winter/early spring are when adult mortality is highest [12]. We take these events into consideration in modelling survival. 


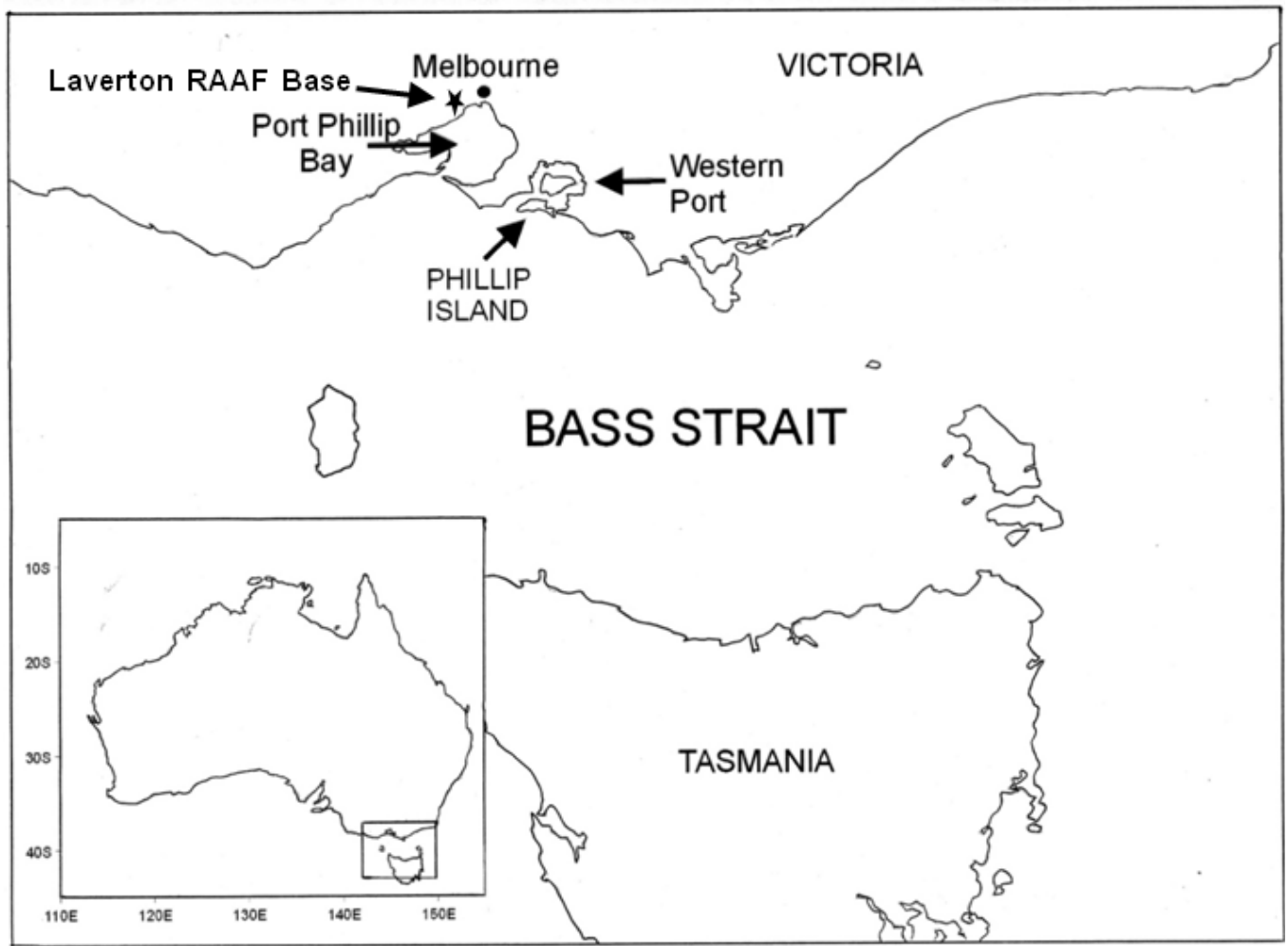

Figure 1: The location of Phillip Island.

The penguin colony on Phillip Island has very high conservation, cultural, scientific and economic significance. The 42 year duration of this study makes it one of the longer running studies of a seabird in Australia and allows rare opportunities to investigate the relationships between the ecology of a seabird and climate over a relatively long period. The importance of this colony means that it is managed carefully in order to protect it from anthropogenic threats [10], and researchers at the Phillip Island Nature Parks are investigating the likely impacts of climate variability and change on the penguins. As part of this, here we investigate the effect of the mean seasonal 
directional wind components, in each of the four cardinal compass directions, on the annual survival probabilities of first-year and adult penguins. The techniques employed here for Little Penguins can be used to analyse markrecapture data for any wildlife species and to determine the potential effect of any climatic variables on the species.

\section{Data and methods}

Our mark-recapture data consist of life history records for 54484 penguins (including birds marked as chicks and as adults of unknown age) collected over a 42 year period, during visits to penguin burrows on Phillip Island. Such a long term data set is extremely rare for any species. 'Mark' refers to the first time a bird is encountered when it is marked with an identifying tag (a metal flipper band or an electronic transponder). A subsequent live encounter is termed 'recapture'.

Wind data are from Laverton RAAF Base $\left(37^{\circ} 52^{\prime} \mathrm{S}, 144^{\circ} 46^{\prime} \mathrm{E}\right)$, about $100 \mathrm{~km}$ from the study area. The data comprise twice daily $(9 \mathrm{am}$ and $3 \mathrm{pm}$ ) readings of wind magnitude $\left(\mathrm{ms}^{-1}\right)$ and direction ( ${ }^{\circ}$ true bearing). The Laverton site is used both for consistency with previous studies [20] and because adult penguins in particular spend a considerable amount of time at Port Phillip Bay in winter and early spring [19]. Wind data from Phillip Island are available only since 1981, and are of relatively poor quality, so cannot be used.

We consider the effect of the wind component from each of the four compass directions on penguin survival, by using as covariates the seasonal means of the maximum daily wind component from each direction. Wind components are non-negative: for example an easterly component is positive if the wind direction is between 0 and $180^{\circ}$, and zero for a direction between $180^{\circ}$ and $360^{\circ}$. In the period 1967 to 2008 there were 30682 wind readings, only $40(0.13 \%)$ of which were missing. Missing values were ignored when calculating daily maxima and seasonal means. 
The parameters used are the annual survival probabilities and the recapture probabilities, defined as follows. Let $\phi_{i, j}$ be the probability that a bird survives the $j$ th calendar year, given it was alive at the start of the year, where $i=1$ in the first year of life and $i=2$ for each subsequent year of life. Also let $p_{i, j}$ be the probability that a bird is recaptured in the $(j+1)$ th breeding season, given it was alive then, where $i=1$ in the first year of life, $i=2$ in the second year, and $i=3$ in each subsequent year. We assume an 'age + time' structure for the recapture probability:

$$
\operatorname{logit}\left(p_{i, j}\right)=\alpha_{i}+\beta_{j},
$$

where $\operatorname{logit}(x)=\log [x /(1-x)]$ is the logistic transform. Here $\alpha_{1}, \alpha_{2}$ and $\alpha_{3}$ are constants specific to the age groups, whereas the $\beta_{j}$ are time dependent parameters. This implies that time variation of the recapture probability is the same for each age group. This model is a realistic reflection of the Little Penguin lifestyle. Separate annual survival probabilities are used for the first and subsequent years of life as first-year birds are particularly at risk due to inexperience and internal parasitic loads [10, 12, 14]. Furthermore, since young birds go to sea and return to Phillip Island to breed at two or three years of age, separate recapture probabilities are used for the first, second, and subsequent years of life [11, 22, 26].

The likelihood, which is the probability of the observed data occurring under the model, is derived as follows. With a slight abuse of notation, we redefine the parameters for this paragraph only, so that the subscript $i$ in $\phi_{i, j}$ and $p_{i, j}$ refers to the ith bird. The observed mark-recapture history of this bird is shown as an indicator vector $h_{i}$, of length equal to the length of the study (here 42 years), with an entry 1 indicating that the bird was seen and a 0 that it was not seen. For example,

$$
h_{i}=(0,0,0,1,0,1,0,1,0,0, \ldots, 0)
$$

means that bird $i$ was initially captured in year 4 , and was seen again in years 6 and 8, then never seen again. Let $c_{i}$ and $k_{i}$ denote the years of first and last capture, respectively, and let $\chi_{r}$ denote the probability of never being 
seen again after year $r$. Clearly $\chi_{42}=1$, and the remaining values of $\chi$ can be found by working backwards through the recurrence relation

$$
\chi_{\mathrm{r}}=1-\phi_{\mathrm{r}}+\phi_{\mathrm{r}}\left(1-\mathrm{p}_{\mathrm{r}}\right) \chi_{\mathrm{r}+1} .
$$

We write the probability of the history $h_{i}$, conditional on the initial capture at $c_{i}$, as

$$
L_{i}=\left\{\prod_{j=c_{i}}^{k_{i}-1} \phi_{i, j} p_{i, j}^{h_{i, j+1}}\left(1-p_{i, j}\right)^{1-h_{i, j+1}}\right\} \chi_{k_{i}},
$$

and this is the likelihood for bird $i$. Assuming that birds behave independently, the likelihood for the whole data set is the product $L=\prod_{i} L_{i}$ over all birds. This is known as the Cormack-Jolly-Seber model [7, 16, 25].

The likelihood is then maximised (or, equivalently, the negative of the loglikelihood is minimised) using the Matlab fmincon function. Computation of this likelihood is slow when there are a lot of animals in the data. If all parameters depend only on age and time, as in the present case, or only on cohort and time, then it is more efficient to use a simple modification of this formula, in which birds are first collected together by cohort [4, 28].

Model selection is via the Akaike information criterion (AIC) [3]. At the sth stage of modelling, we fit

$$
\operatorname{logit}\left(\phi_{i, j}\right)=b_{0}+b_{1} V_{1, j}+\cdots+b_{s} V_{s, j},
$$

where the $V_{r}$ are the wind covariates. When modelling first year survival $\phi_{1, j}$, we allow adult survival $\phi_{2, j}$ to be fully time varying, and vice versa. The fit of a model with log-likelihood $\ell$ is measured by the proportion of the total (time) deviance explained, $\left(\ell-\ell_{0}\right) /\left(\ell_{\text {full }}-\ell_{0}\right)$, where $\ell_{0}$ is the log-likelihood of the null model, with constant survival, and $\ell_{\text {full }}$ is that of the full model, with fully time varying survival [18, p. 33].

There may be a lag of several months in the effect of wind on survival $[8,20]$. To account for lags, the annual survival probability over calendar year $j$ is made dependent on wind covariates chosen from an 18 month period, from 
winter in the previous year (that is, 1 Jun-31 Aug in calendar year $j-1$ ) denoted 'WiP', to spring in the current year, denoted 'SpC'.

\section{Results and discussion}

\subsection{First year survival}

The best fitting first stage model is that of the southerly wind component in the previous winter (S_WiP, Table 1), with the positive regression coefficient (with standard error) $b_{1}=0.295(0.038)$ indicating that a higher average southerly wind in the winter prior to breeding is associated with higher first year survival in the following calendar year. This lag of several months in the effect of wind on survival is similar to previously noted lags in the effect of sea surface temperature on the timing of breeding [8] and of the temperature gradient on adult mass and timing of breeding [20]. The effect may be indirectfor example, good feeding conditions in the winter preceding breeding allow adults to progress through the breeding season in better condition, possibly breed earlier [21] and confer the advantage to their chicks through greater meal masses, higher fledging weights and consequently higher first year survival [9]. Conversely it may be direct - for example, a better food supply for chicks postfledging because of processes commencing in winter several months earlier. Stronger southerly winds during winter increase the amount of sub-Antarctic surface water entering Bass Strait [24]. Southerly and westerly winds are suggested as mechanisms for moving nutrient rich water into Bass Strait and closer to Phillip Island [20]. It is likely that this nutrient rich water promotes areas of higher primary and secondary productivity which attract fish. The closer these areas are to Phillip Island, the more food is likely to be available to penguins which have a relatively limited daily foraging range when raising chicks $[6,15]$.

At the second stage, allowing for S_WiP, the best fitting covariate is easterly 
Table 1: AIC values for various models for the first year survival probabilities. In each case the adult survival is fully time varying, whereas the first year survival depends on covariates as shown. 'N_WiP' denotes 'mean wind magnitude from the north in winter of the previous year', while ' $\mathrm{E} A \mathrm{AuC}$ ' is 'mean wind magnitude from the east in autumn of the current year', etc. At the first stage only a single covariate is used. The second stage uses the best model (shown in bold) from the first stage, plus each of the other covariates, and so on.

\begin{tabular}{rrrrr}
\hline Covariate & \multicolumn{4}{c}{ Stage } \\
& 1st & 2nd & 3rd & 4 th \\
\hline N_WiP & 480.69 & 407.70 & 335.83 & 304.18 \\
N_SpP & 457.27 & 414.80 & 363.45 & 314.93 \\
N_SuC & 482.64 & 417.99 & 372.62 & 320.94 \\
N_AuC & 456.62 & 403.66 & 338.45 & $\mathbf{2 9 2 . 8 6}$ \\
N_WiC & 471.80 & 426.15 & 372.85 & 316.42 \\
N_SpC & 475.22 & 424.83 & 367.37 & 306.63 \\
E_WiP & 483.51 & 423.79 & 373.22 & 320.03 \\
E_SpP & 453.02 & 422.02 & 362.71 & 315.22 \\
E_SuC & 456.73 & $\mathbf{3 7 1 . 3 8}$ & & \\
E_AuC & 477.57 & 410.14 & 373.18 & 320.88 \\
E_WiC & 474.67 & 426.81 & 361.17 & 319.48 \\
E_SpC & 478.25 & 425.17 & 318.95 & \\
S_WiP & 424.84 & & & \\
S_SpP & 463.23 & 418.94 & 336.23 & 298.81 \\
S_SuC & 475.18 & 426.81 & 372.43 & 317.35 \\
S_AuC & 482.37 & 419.94 & 370.74 & 315.03 \\
S_WiC & 477.69 & 424.22 & 368.07 & 320.75 \\
S_SpC & 479.94 & 424.37 & 373.33 & 317.81 \\
W_WiP & 472.09 & 413.90 & 372.56 & 314.83 \\
W_SpP & 484.80 & 420.90 & 372.82 & 320.50 \\
W_SuC & 474.16 & 403.65 & 368.56 & 320.83 \\
W_AuC & 483.42 & 426.13 & 370.95 & 320.92 \\
W_WiC & 480.66 & 426.52 & 370.95 & 320.10 \\
W_SpC & 466.77 & 420.40 & 365.74 & 300.86 \\
\hline
\end{tabular}


wind in the current summer (E_SuC, Table 1). The regression coefficient of S_WiP is only slightly changed, at $b_{1}=0.376(0.041)$, and that of E_SuC, $b_{2}=-0.567(0.076)$, means that a higher average easterly wind in the summer of fledging is associated with lower first year survival. Easterly winds in Bass Strait are expected to have a negative effect on survival as they are likely to impede the movement of the nutrient rich water and associated fish towards Phillip Island. This is more important when chicks are fledging and dependent on food being available relatively close to the colony.

At the third stage, the next best covariate is easterly wind in the current spring (E_SpC, Table 1). The regression coefficient of S_WiP is $b_{1}=0.365(0.040)$, again almost unchanged, of E_SuC is $b_{2}=-1.004$ (0.097), and of E_SpC is $b_{3}=0.522(0.070)$, with this last value indicating that higher easterly wind in the current spring is associated with increased survival. It is surprising that easterly winds in spring have a positive influence on first year survival in that calendar year, given that the same winds have a negative effect some months earlier (see above). This apparent contradiction may reflect our lack of knowledge of the potential mechanisms linking climatic variables with the production and distribution of fish in Bass Strait. However, there is a substantial correlation (coefficient $=0.36$ ) between E_SuC and E_SpC, which has caused a large change in $b_{2}$ from the second stage. At the second stage, E_SpC is not a worthwhile explanatory variable (Table 1). It appears likely that the appearance of E_SpC at the third stage is a spurious consequence of this correlation.

Finally, at the fourth stage, the next best covariate is northerly wind in the current autumn ( $\mathrm{N} \_\mathrm{AuC}$, Table 1$)$. The first three regression coefficients are almost unchanged from the third stage, and that of $\mathrm{N}_{-} \mathrm{AuC}$ is $\mathrm{b}_{4}=0.205(0.039)$. This positive effect on survival is also surprising as we expect northerly winds to have a negative effect on first year survival for the reasons given above.

The inclusion of each of these four covariates is well justified in terms of AIC, with substantial reductions at each stage of the modelling (Table 1). In fact, S_WiP accounts for $12.0 \%$ of the deviance (time variation) at the first stage. 
At the second stage E_SpC accounts for a further $11.0 \%$, and $\mathrm{E} \_\mathrm{SpC}$ and $\mathrm{N} \_\mathrm{AuC}$ account for a further $10.8 \%$ and $5.6 \%$ respectively. The four covariates jointly account for $39.4 \%$ of the deviance. These values are calculated from Table 1 and from the AIC values of $\mathbf{4 8 2 . 9 2}$ for the null model, where $\phi_{1}$ is constant, and 60.72 for the full model, where $\phi_{1}$ is fully time varying. The correlations between the four covariates, apart from that between E_SuC and E_SpC, are low, with absolute values of 0.15 or less.

\subsection{Adult survival}

The best first stage model is that of the northerly wind in the current autumn (N_AuC, Table 2), with the positive regression coefficient $\mathrm{b}_{1}=0.313(0.026)$ indicating that stronger northerly winds in the autumn following moult are associated with increased adult survival in that calendar year. Autumn is a time of high adult mortality [12] and it is not readily apparent how northerly winds at this time could improve annual adult survival. These winds are expected to push nutrient laden water and accompanying fish further off-shore, thereby making it potentially harder, rather than easier, for penguins to access food. Our current understanding of the mechanisms connecting wind and productivity in Bass Strait is inadequate to provide a biological explanation for this correlation.

At the second stage, the best fitting covariate is easterly wind in the current summer (E_SuC, Table 2). The regression coefficient of $N_{-} A u C$ is similar, at $b_{1}=0.394(0.028)$, and that of E_SuC, $b_{2}=-0.487$ (0.041), meaning higher easterly winds in summer are associated with lower adult survival. Notably, easterly winds in summer have the same effect on first year survival. Mickelson et al. [20] found that a decreased sea temperature gradient resulted in higher penguin weights and earlier breeding. They hypothesised that increased westerly winds in winter were responsible for the decreasing gradient and that these winds pushed nutrient rich water and associated fish further into Bass Strait and closer to Phillip Island. The same chain of events might explain 
Table 2: AIC values for various models for the adult annual survival probabilities. In each case the first year survival is fully time varying, while the adult survival depends on covariates as shown. At the first stage only a single covariate is used. The second stage uses the best model (shown in bold) from the first stage, plus each of the other covariates, and so on.

\begin{tabular}{rrrrr}
\hline Covariate & \multicolumn{4}{c}{ Stage } \\
& 1st & 2nd & 3rd & 4 th \\
\hline N_WiP & 1027.44 & 874.52 & 721.92 & 675.22 \\
N_SpP & 1035.86 & 891.01 & 731.20 & 670.64 \\
N_SuC & 984.87 & 771.30 & 699.88 & 638.56 \\
N_AuC & 891.16 & & & \\
N_WiC & 1031.52 & 893.15 & 751.10 & 679.65 \\
N_SpC & 1035.41 & 885.79 & 749.84 & 676.20 \\
E_WiP & 969.78 & 749.97 & 698.87 & 642.53 \\
E_SpP & 1037.80 & 891.99 & 733.38 & 642.96 \\
E_SuC & 955.44 & 749.11 & & \\
E_AuC & 1028.98 & 883.39 & 704.22 & 637.30 \\
E_WiC & 1000.48 & 778.01 & 721.45 & 679.87 \\
E_SpC & 1037.71 & 888.60 & 711.54 & 628.47 \\
S_WiP & 1006.33 & 832.23 & 732.40 & 676.64 \\
S_SpP & 1026.82 & 892.13 & 708.31 & 668.34 \\
S_SuC & 971.99 & 849.97 & 699.81 & 670.49 \\
S_AuC & 1022.87 & 885.85 & 743.38 & 660.89 \\
S_WiC & 957.03 & 813.00 & 745.90 & 671.39 \\
S_SpC & 1030.55 & 890.35 & 721.39 & 674.79 \\
W_WiP & 1037.75 & 889.47 & 746.66 & 679.94 \\
W_SpP & 1034.12 & 851.02 & 739.26 & 673.88 \\
W_SuC & 956.38 & 795.24 & 695.13 & 662.32 \\
W_AuC & 1030.17 & 892.73 & 751.11 & 662.34 \\
W_WiC & 992.50 & 863.31 & $\mathbf{6 7 7 . 9 4}$ & \\
W_SpC & 1005.61 & 868.21 & 706.45 & $\mathbf{6 2 2 . 4 9}$ \\
\hline
\end{tabular}


the association noted here, whereby increased easterly winds push nutrient rich waters away from Phillip Island, lowering fish availability and decreasing adult survival as a consequence.

At the third stage, the next best covariate is westerly wind in the current winter (W_WiC, Table 2). The regression coefficients of N_AuC and E_WiP are similar to stage 2 , and that of W_WiC is $b_{3}=0.161$ (0.019), with this last value indicating that higher westerly wind in the winter following moult is associated with increased survival during that calendar year. This supports the above hypothesis that westerly winds move nutrient rich waters into Bass Strait and closer to Phillip Island, thus providing more accessible food resources for penguins [20, 24].

Finally, at the fourth stage, the next best covariate is westerly wind in the current spring (W_SpC, Table 2). The first three regression coefficients are similar to those from the third stage, with $b_{1}=0.373(0.028), b_{2}=-0.616(0.042)$ and $b_{3}=0.180(0.019)$, and that of $W_{-} S p C$ is $b_{4}=-0.169(0.022)$, so that higher westerly wind in the spring following moult is associated with decreased survival during that calendar year. This result contradicts our current hypothesis of westerly winds improving penguin survival and suggests that this hypothesis may oversimplify the complexities of the link between climatic variables and penguin survival.

The inclusion of each of these four covariates is well justified statistically, with substantial reductions in AIC at each stage of the modelling (Table 2). The four covariates jointly account for $40.0 \%$ of the time variation, that is, of the difference in deviance between the null model, where $\phi_{2}$ is constant, and the full model, where $\phi_{2}$ is fully time varying, N_AuC accounts for $13.9 \%$, E_SuC accounts for a further $13.6 \%$, and W_WiC and W_SpC account for a further $6.9 \%$ and $5.4 \%$ respectively. These values are calculated from Table 2 and from the AIC values for the null model (1035.81) and full model (60.72). The correlations between the four covariates are low, all 0.17 or less. 


\section{Conclusion}

We analysed a long term mark-recapture data set for Little Penguins on Phillip Island, and used mean seasonal wind components from the four compass directions as covariates for the first-year and adult survival probabilities.

Results showed that first year survival increased with increasing southerly winds in the winter before hatching. Since southerly winds are thought to move nutrient rich water, and associated fish, closer to Phillip Island, they may affect first-year birds indirectly, due to improved conditions for their parents, or via a lagged effect, resulting in a better food supply post-fledging. Higher easterly winds in the summer of fledging were associated with reduced survival of both first-year and adult birds. This suggests that easterly winds, which may impede the flow of nutrient rich water into Bass Strait, make it more difficult for newly fledged birds to forage as well as for adults that may still be feeding chicks or, in late summer, preparing for moult.

Higher westerly winds in the spring were associated with reduced adult survival in that calendar year. Stronger northerly winds in the autumn following the moult period, and westerly wind in the following winter, were both associated with increased survival. The covariates influence adult survival independently, suggesting that there are several mechanisms by which the wind influences these birds. While southerly and westerly winds are thought to move nutrient rich water closer to Phillip Island, easterly and northerly winds would be expected to impede this flow. Our current understanding of the mechanisms connecting wind and productivity in Bass Strait is insufficient to interpret the observed effect of westerly and northerly winds on adult survival.

Future work will examine the effect of the overall wind magnitude on penguin survival, as well as the possible existence of a threshold wind strength, with winds stronger than this threshold having an effect on survival. 
Acknowledgements We are indebted to the staff of the Phillip Island Nature Parks, particularly Ros Jessop and Leanne Renwick, and to members of the Penguin Study Group and the Australian Bird and Bat Banding Scheme for providing the penguin data upon which this study is based. We are also grateful to the Australian Bureau of Meteorology for providing the wind data, to Paul Sandery and Andrew Kiss for their advice regarding Bass Strait oceanography, and to Harvinder Sidhu for his useful comments on this manuscript.

\section{References}

[1] D. G. Ainley, J. Russell, S. Jenouvrier, E. Woehler, P. O. Lyver, W. R. Fraser, and G. L. Kooyman. Antarctic penguin response to habitat change as earth's troposphere reaches $2^{\circ} \mathrm{C}$ above preindustrial levels. Ecological Monographs, 80:49-66, 2010.

http://www. esajournals .org/doi/pdf/10.1890/08-2289.1 C1013

[2] C. J. Brown, E. A. Fulton, A. J. Hobday, R. J. Matear, H. P. Possingham, C. Bulman, V. Christensen, R. E. Forrest, P. C. Gehrke, N. A. Gribble, S. P. Griffiths, H. Lozano-Montes, J. M. Martin, S. Metcalf, T. A. Okey, R. Watson, and A. J. Richardson. Effects of climate-driven primary production changes on marine food webs: implications for fisheries and conservation. Global Change Biology, 16:1194-1212, 2010. doi:10.1111/j.1365-2486.2009.02046.x C1013

[3] K. Burnham and D. Anderson. Model selection and multimodel inference: a practical information-theoretic approach. Springer Verlag, 2002. C1018

[4] E. A. Catchpole, S. N. Freeman, B. J. T. Morgan, and M. P. Harris. Integrated recovery/recapture data analysis. Biometrics, 54:33-46, 1998. doi:10.2307/2533993 C1018 
[5] L. E. Chambers, C. A. Devney, B. C. Congdon, N. Dunlop, E. J. Woehler, and P. Dann. Observed and predicted effects of climate on Australian seabirds. Emu, 111:235-251, 2011. doi:10.1071/MU10033 C1013

[6] M. Collins, J. M. Cullen, and P. Dann. Seasonal and annual foraging movements of Little Penguins from Phillip Island, Victoria. Wildlife Research, 26:705-721, 1999. doi:10.1071/WR98003 C1019

[7] R. M. Cormack. Estimates of survival from the sighting of marked animals. Biometrika, 51:429-438, 1964. doi:10.1093/biomet/51.3-4.429 C1018

[8] J. M. Cullen, L. E. Chambers, P. C. Coutin, and P. Dann. Predicting onset and success of breeding in little penguins Eudyptula minor from ocean temperatures. Marine Ecology Progress Series, 378:269-278, 2009. doi:10.3354/meps07881 C1018, C1019

[9] P. Dann. An experimental manipulation of clutch size in the Little Penguin Eudyptula minor. Emu, 88:101-103, 1988. doi:10.1071/MU9880101 C1019

[10] P. Dann. Distribution, population trends and factors influencing the population size of Little Penguins Eudyptula minor on Phillip Island, Victoria. Emu, 91(5):263-272, 1992. doi:10.1071/MU9910263 C1015, C1017

[11] P. Dann and J. M. Cullen. Survival, patterns of reproduction and lifetime reproductive output in the Little Blue Penguins (Eudyptula minor) on Phillip Island, Victoria, Australia. In L. S. Davis and J. T. Darby, editors, Penguin Biology, pages 63-84. Academic Press, San Diego, 1990. C1014, C1017

[12] P. Dann, J. M. Cullen, R. Thoday, and R. Jessop. Movements and patterns of mortality at sea of Little Penguins Eudyptula minor from 
Phillip Island, Victoria. Emu, 91(5):278-286, 1992.

doi:10.1071/MU9910278 C1014, C1017, C1022

[13] S. T. Garnett and G. M. Crowley. The Action Plan for Australian Birds 2000. Environment Australia, Canberra, 2000.

http://www. environment.gov.au/biodiversity/threatened/ publications/action/birds2000/index.html C1013

[14] K. E. Harrigan. Causes of mortality of Little Penguins Eudyptula minor in Victoria. Emu, 91:273-277, 1992. C1017

[15] A. J. Hoskins, P. Dann, Y. Ropert-Coudert, A. Kato, A. Chiaradia, D. P. Costa, and J. P. Y. Arnould. Foraging behaviour and habitat selection at sea in Little Penguins Eudyptula minor during the chick-guard stage of breeding. Marine Ecology Progress Series, 366:293-303, 2008. C1019

[16] G. M. Jolly. Explicit estimates from capture-recapture data with both death and immigration-stochastic models. Biometrika, 52:225-247, 1965. doi:10.2307/2333826 C1018

[17] B. R. King, J. T. Hicks, and J. Cornelius. Population changes, breeding cycles and breeding success over six years in a seabird colony at Michaelmas Cay, Queensland. Emu, 92:1-10, 1992. doi:10.1071/MU9920001 C1013

[18] P. McCullagh and J. A. Nelder. Generalized Linear Models. Chapman and Hall, London, 2nd edition, 1989. C1018

[19] C. McCutcheon, P. Dann, M. Salton, L. Renwick, A. J. Hoskins, A. M. Gormley, and J. P. Y. Arnould. The foraging range of Little Penguins (Eudyptula minor) during winter. Emu (online first), 2011. doi:10.1071/MU10078 C1016

[20] M. J. Mickelson, P. Dann, and J. M. Cullen. Sea temperature in Bass Strait and breeding success of the Little Penguins Eudyptula minor at Phillip Island, South-eastern Australia. Emu, 91(5):355-368, 1992. doi:10.1071/MU9910355 C1013, C1016, C1018, C1019, C1022, C1024 
[21] I. C. T. Nisbet and P. Dann. Reproductive performance of little penguins in relation to year, age, pair-bond duration, breeding date and individual quality. Journal of Avian Biology, 40:296-308, 2009. doi:10.1111/j.1600-048X.2008.04563.x C1019

[22] P. N. Reilly and J. M. Cullen. The Little Penguin Eudyptula minor in Victoria. II: Breeding. Emu, 81:1-19, 1981. doi:10.1071/MU9810001 C1014, C1017

[23] Y. Ropert-Coudert, A. Kato, and A. Chiaradia. Impact of small-scale environmental perturbations on local marine food resources: a case study of a predator, the little penguin. In Proceedings of the Royal Society B, volume 276, pages 4105-4109, 2009.

doi:10.1098/rspb.2009.1399 C1013, C1014

[24] P. A. Sandery. Seasonal variability of water mass properties in Bass Strait: three-dimensional oceanographic modelling studies. $\mathrm{PhD}$ thesis, Flinders University, Adelaide, 2007. http://catalogue.flinders.edu. au/local/adt/public/adt-SFU20070831.093503 C1019, C1024

[25] G. A. F. Seber. A note on the multiple recapture census. Biometrika, 52:249-259, 1965. doi:10.1093/biomet/52.1-2.249 C1018

[26] L. A. Sidhu. Analysis of recovery-recapture data for Little Penguins. $\mathrm{PhD}$ thesis, School of Physical, Environmental and Mathematical Sciences, The University of New South Wales at the Australian Defence Force Academy, 2007. C1017

[27] L. A. Sidhu, E. A. Catchpole, and P. Dann. Mark-recapture-recovery modeling and age-related survival in Little Penguins Eudyptula minor. The Auk, 124:815-827, 2007. doi:10.1642/0004-8038(2007)124[815:MMAASI]2.0.CO;2 C1014

[28] L. A. Sidhu, E. A. Catchpole, and P. Dann. Modelling banding effect and tag loss for Little Penguins Eudyptula minor. In W. McLean and A. J. Roberts, editors, Proceedings of the 15th Biennial Computational 
Techniques and Applications Conference, CTAC-2010, volume 52 of ANZIAM Journal, pages C206-C221, 2011. http://journal.austms . org.au/ojs/index.php/ANZIAMJ/article/view/3941 [June 6, 2011]. C1018

\section{Author addresses}

1. L. B. Ganendran, School of Physical, Environmental and Mathematical Sciences, University of New South Wales at the Australian Defence Force Academy, Australia.

2. L. A. Sidhu, School of Physical, Environmental and Mathematical Sciences, University of New South Wales at the Australian Defence Force Academy, Australia.

mailto:1.sidhu@adfa.edu.au

3. E. A. Catchpole, School of Physical, Environmental and Mathematical Sciences, University of New South Wales at the Australian Defence Force Academy, Australia.

4. P. Dann, Research Department, Phillip Island Nature Parks, PO Box 97, Cowes, Phillip Island, Australia.

5. L. E. Chambers, Centre for Australian Weather and Climate Research, Bureau of Meteorology, GPO Box 1289, Melbourne, Australia. 